\title{
LESSINGIANTHUS MAGNIFICUS DEBLE, DEMATTEIS \& MARCHIORI (ASTERACEAE), NOVA ESPÉCIE DO NORTE DO URUGUAI E RIO GRANDE DO SUL (BRASIL) ${ }^{1}$
}

\author{
LEONARDO PAZ DEBLE ${ }^{2}$ MASSIMILIANO DEMATTEIS ${ }^{3}$ \\ JOSÉ NEWTON CARDOSO MARCHIORI ${ }^{4}$
}

\section{RESUMO}

É descrita e ilustrada uma nova espécie de Asteraceae: Lessingianthus magnificus Deble, Dematteis \& Marchiori, do norte do Uruguai e Rio Grande do Sul (Brasil). Relacionada a Lessingianthus macrocephalus (Less.) H. Rob., ela difere pelo tipo de indumento das folhas, bem como pelas brácteas involucrais obtusas e densamente lanosas.

Palavras chave: Lessingianthus magnificus, Asteraceae, Vernonieae, nova espécie.

\section{ABSTRACT}

A new species of Asteraceae is presently described and illustrated: Lessingianthus magnificus Deble, Dematteis \& Marchiori, from the State of Rio Grande do Sul (Brazil) and northern Uruguay. Close to Lessingianthus macrocephalus (Less.) H. Rob., it differs by the type of hairs on leaves, as well as by the obtuse and dense lanate involucral bracteis.

Key words: Lessingianthus magnificus, Asteraceae, Vernonieae, new species.

\section{INTRODUÇÃO}

O exame de exsicatas conservadas em herbário revelou a existência de uma espécie de Lessingianthus que não corresponde a nenhuma espécie conhecida do gênero e que estava confundida com L. macrocephalus (Less.) $\mathrm{H}$. Rob. A análise do material-tipo de $L$. macrocephalus demonstrou que o mesmo possui folhas discolores, com a parte abaxial incanotomentosa, bem como brácteas involucrais internas agudas e incano-tomentosas. $\mathrm{O}$ novo táxon, ao contrário, apresenta folhas suavemente discolores, ferrugíneo-tomentosas na parte abaxial, e brácteas involucrais sempre obtusas e densamente lanosas.

\section{DESCRIÇÃO}

Lessingianthus magnificus Deble, Dematteis \& Marchiori, sp. nov. ${ }^{5}$

Suffrutex erectus usque $100 \mathrm{~cm}$ altus, caulibus superne ramosis. Caulibus striatis, dense ferrugineo-tomentosis, usque ad inflorescentiam foliosis. Folia alterna (internodiis 1-4,5 cm), leviter discolora, ovata vel ovato-lanceolata, 3,5-13 cm longa, 1,5-5 cm lata, coriacea, sessilia vel breviter petiolata (petiolis cylindraceis, dense tomentosis, 1-4 mm longis); laminis inferne dense ferrugineotomentosis, superne glabris vel subglabris, margine crenulatis, apice leviter acutis ad obtusis, basi cuneatis. Capitula magna, sessilia in cincinnis (2-4 capitulis) 7-22 cm longis, terminalibus vel axillaribus dispositis. Bracteae inflorescentiarum lanceolatae foliaceae, $2-4 \mathrm{~cm}$ longae, 0,5-1,5 cm latae. Involucrum campanulatum, 20-24 $\mathrm{mm}$ altum, 20-26 mm crassum. Bracteis involucralibus 7-8seriatis, obtusis et cum dorso dense lanosis; externis ovato-

\footnotetext{
Artigo recebido em 24/10/2005 e aceito para publicação em 07/11/2005.

2 Biólogo, MSc. Bolsista da CAPES, doutorando do Programa de Pós-Graduação em Engenharia Florestal, Centro de Ciências Rurais, Universidade Federal de Santa Maria, CEP 97105-900, Santa Maria (RS). deble.biol@bol.com.br

3 Biólogo, Doutor em Ciências Biológicas, Instituto de Botánica del Nordeste (UNNE-CONICET), C. C. 209, 3400, Corrientes, Argentina. dematteisar@yahoo.com.ar

${ }^{4}$ Engenheiro Florestal, Dr., bolsista de Produtividade em Pesquisa do CNPq, Professor Titular do Departamento de Ciências Florestais, Universidade Federal de Santa Maria, CEP 97105-900, Santa Maria (RS). balduinia@mail.ufsm.br

5 Etimologia: do latim - magnífico, suntuoso -, em alusão ao tamanho dos capítulos.
} 


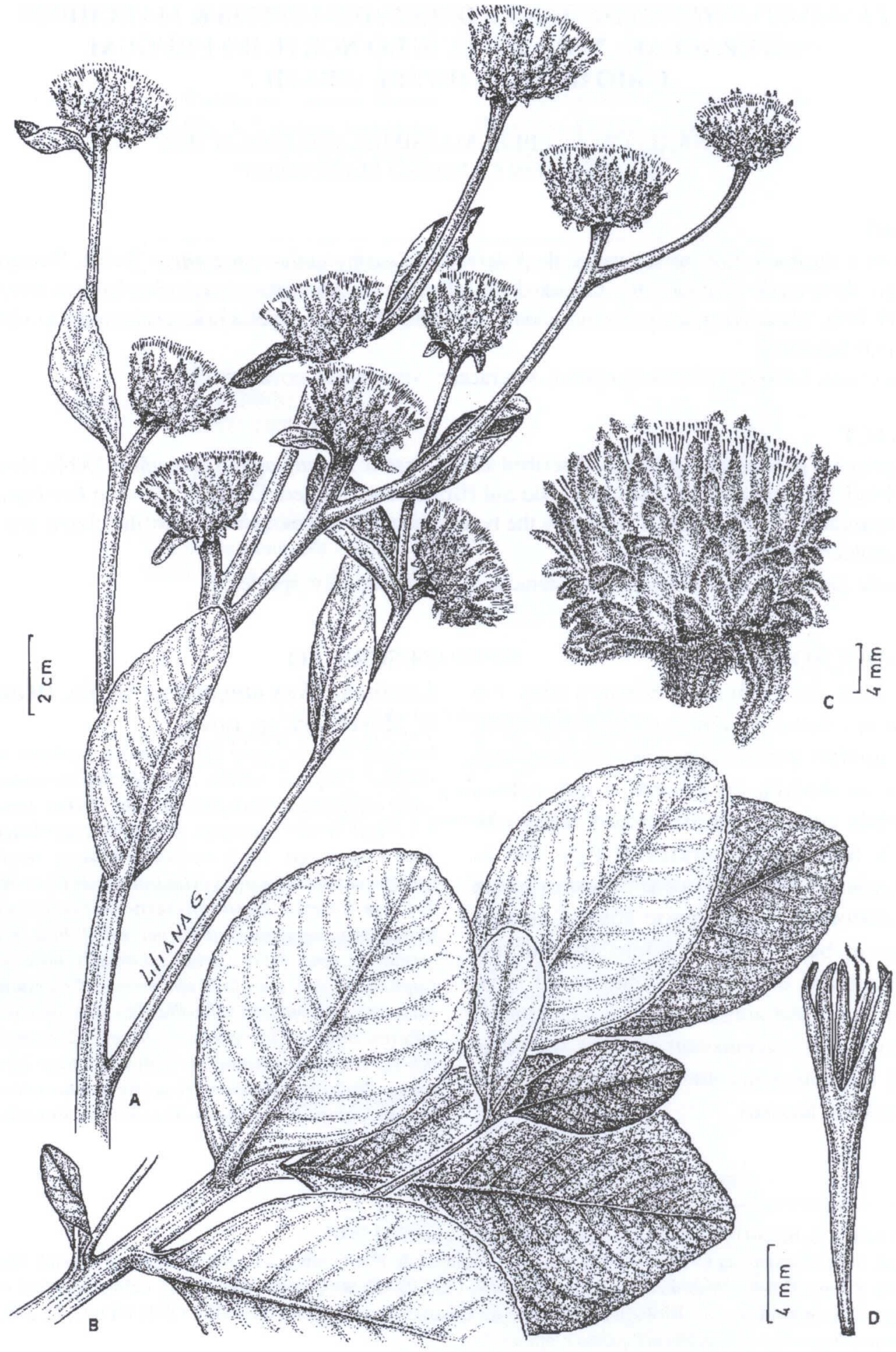

FIGURA 1 - Lessingianthus magnificus Deble, Dematteis \& Marchiori. Ápice do ramo florífero (A). Base de ramo (B). Capítulo (C). Flor (D). 
oblongis, 7-12 mm longis, $3 \mathrm{~mm}$ latis; mediis oblongis, $12-15 \mathrm{~mm}$ longis, $3 \mathrm{~mm}$ latis; internis oblongis ad oblongospathulatis, $15-20 \mathrm{~mm}$ longis, $4 \mathrm{~mm}$ latis. Flores violaceis, 50-70; corolla 15-18 mm longa, lobis linear-lanceolatis,7$9 \mathrm{~mm}$ longis; stylo $18-20 \mathrm{~mm}$ longo, rami $6 \mathrm{~mm}$; antherae $5 \mathrm{~mm}$ longae. Pappus albidus; setis externis brevibus, planis, $2 \mathrm{~mm}$ longis; internis capillaceis, $10 \mathrm{~mm}$ longis. Achaenia (valde inmatura) $3 \mathrm{~mm}$ longa.

TIPO - BRASIL, Rio Grande do Sul, Nova Esperança do Sul, Gruta da Linha 1, flores violáceas, arbusto de até $1 \mathrm{~m}$, J. N. C. Marchiori 140, 27.XII.1985. Holotypus SI.

Subarbusto ereto, de até $100 \mathrm{~cm}$ de altura, ramoso na parte superior (Figura 1a). Ramos estriados, densamente ferrugíneo-tomentosos, com 3-9 mm de diâmetro, folhosos até a inflorescência (Figura 1a, 1b). Folhas alternas (entrenós de 1-4,5 cm), ovadas ou ovadolanceoladas (3,5-13 cm de comprimento por 1,5$5 \mathrm{~cm}$ de largura), coriáceas, sésseis ou brevepedunculadas (pedúnculos mais ou menos cilíndricos, densamente tomentosos, de 1-4 $\mathrm{mm}$ ), suavemente discolores, densamente ferrugíneo-tomentosas na parte abaxial e glabrescentes na parte adaxial, de margens crenuladas, ápice levemente agudo a obtuso e base cuneada (Figura 1b). Capítulos grandes, sésseis, dispostos em cincínios de $7-22 \mathrm{~cm}$ de comprimento e 2-4 capítulos, separados por entrenós de 1,5-8 cm de comprimento (Figura 1a). Brácteas foliáceas lanceoladas $(2-4 \mathrm{~cm}$ de comprimento por 0,5-1,5 cm de largura), gradativamente menores em direção ao ápice (Figura 1a). Invólucro campanulado, de 20-24 mm de altura por 20-26 mm de diâmetro (Figura 1c). Brácteas involucrais 7-8-seriadas, todas obtusas no ápice e densamente lanosas (Figura 1c); as externas, ovado-oblongas, de 7-12 mm de comprimento por $3 \mathrm{~mm}$ de largura (Figura 1c); as medianas, oblongas, de $12-15 \mathrm{~mm}$ de comprimento por $3 \mathrm{~mm}$ de largura (Figura 1c); as internas, oblongas a oblongo-espatuladas, de 15-20 mm de comprimento por $4 \mathrm{~mm}$ de largura (Figura 1c). Flores, 50-70; corola violácea, de 15-18 mm de comprimento, com lóbulos linearlanceolados de 7-9 mm de comprimento (Figura 1d). Estigma de 18-20 mm de comprimento, com ramas de $6 \mathrm{~mm}$. Anteras de $5 \mathrm{~mm}$ de comprimento. Pápus branco, com série externa paleácea, de $2 \mathrm{~mm}$, e interna ciliada, de $10 \mathrm{~mm}$. Aquênios imaturos, de $3 \mathrm{~mm}$ de comprimento.

Paratypi: BRASIL, Rio Grande do Sul, Alegrete, 40 km SE de Alegrete, 5.XII.1978, A. Krapovickas \& C. L. Cristóbal 34166 (C, CTES, SP, P).

Distribuição \& Habitat: Espécie rara, restrita ao norte do Uruguai e Rio grande do Sul (Brasil). Vive em campos pedregosos e arenosos. Floresce e frutifica no verão.

Comentários: Lessingianthus magnificus tem sido confundido com $L$. macrocephalus pela forma e tamanho das folhas, bem como pelo tipo de inflorescência e tamanho dos capítulos. Lessingianthus macrocephalus apresenta ramos e hipófilo com densa pubescência incana; $L$. magnificus, ao contrário, apresenta pubescência ferrugíneo-lanosa, sem formar uma camada compacta como em L. macrocephalus. As brácteas involucrais de L. macrocephalus apresentam ápice agudo e dorso com pubescência incana, diferença marcante com relação L. magnificus, que apresenta brácteas obtusas e dorso com densa pubescência lanosa. A nova espécie está relacionada, também, a $L$. asterifolius (Mart. ex DC.) H. Rob, da qual difere pela forma das folhas e tamanho dos capítulos. Lessingianthus asterifolius possui folhas estreitamente lanceoladas e capítulos menores, de $12 \mathrm{~mm}$ de altura.

\section{AGRADECIMENTOS}

A Mirtha Liliana Gómez, pela ilustração.

\section{BIBLIOGRAFIA}

Baker, J. G. Compositae. I. Vernoniaceae. In: Martius, C. F. Flora Brasiliensis, München, Wien, Leipzig, 1873. v. 6, n. 2, p. 1-179.

Robinson, H. Generic and subtribal classification of american Vernonieae. Smithsonian Contrib. Bot., Washington, n. 89, p. 1-116, 1999. 